\title{
KINERJA PUTARAN ROTOR TURBIN AIR SCREW ARCHIMEDES DENGAN VARIASI KEMIRINGAN SUDUT TURBIN
}

\author{
Yudi Setiawan ${ }^{1}$, Eka Sari Wijianti ${ }^{2 *}$, Saparin ${ }^{3}$, Budi Santoso Wibowo ${ }^{4}$, Priyoko Prayitnoadi ${ }^{5}$ \\ ${ }^{12345}$ Jurusan Teknik Mesin Fakultas Teknik, Universitas Bangka Belitung \\ *E-mail: ekasari@ubb.ac.id
}

\begin{abstract}
Abstrak
Turbin Air Screw Archimedes merupakan salah satu pembangkit listrik mikro hidro yang bekerja untuk menghasilkan energi listrik. Sumber aliran air dari pembangkit listrik ini memiliki head yang rendah sehingga sangat cocok digunakan pada aliran kecil seperti irigasi dan sungai kecil. Turbin didesain kemudian dibangun membentuk prototipe dengan panjang screw $1 \mathrm{~m}$, diameter luar $0,3 \mathrm{~m}$, jumlah sudu 15 , dan jarak pitch masingmasing $13 \mathrm{~cm}$. Penelitian dilakukan dengan variasi sudut kemiringan turbin adalah $30^{\circ}, 35^{\circ}$, dan $40^{\circ}$. Hasil penelitian menunjukkan bahwa putaran rotor terbaik dihasilkan oleh sudut $40^{\circ}$. Putaran yang mampu dibangkitkan dengan head $0,67 \mathrm{~m}$, debit aliran 7 liter/detik adalah sebesar $930 \mathrm{Rpm}$ dengan potensi daya listrik sebesar 43,95 watt.
\end{abstract}

Kata kunci: PLTMH, Turbin Air Archimedes, Turbin screw

\begin{abstract}
The Archimedes Screw Turbine is a micro hydropower plant that works to generate electrical energy. The source of water flow from this power plant has a low head so it is suitable for use in small flows such as irrigation and small rivers. The turbine is designed and then built to form a prototype with a screw length of 1 $\mathrm{m}$, an outer diameter of $0.3 \mathrm{~m}$, a number of blades 15, and a pitch distance of $13 \mathrm{~cm}$ each. The research was conducted with variations of the turbine inclination angle of $30^{\circ}, 35^{\circ}$, and $40^{\circ}$. The results showed that the best rotor rotation was produced by an angle of $40^{\circ}$. The rotation that can be generated with a head of $0.67 \mathrm{~m}$, the flow rate of 7 liters/second is 930 Rpm with an electric power potential of 43.95 watts.
\end{abstract}

Keywords: PLTMH, Archimedes Screw Turbine, Screw Turbine

\section{PENDAHULUAN}

Daya aliran air adalah salah satu parameter yang menjadi acuan dalam menentukan efisiensi sebuah turbin. Hakikatnya air selalu mengalir dari tempat yang tinggi ke tempat yang rendah baik secara alami maupun bantuan sebuah media dengan lintasan yang bervariasi, bisa lurus atau miring dimana kondisi tersebut sangat mempengaruhi aliran air. Sejatinya, aliran air tersebut merupakan sumber energi potensial untuk dijadikan pembangkit listrik tenaga air atau PLTA. PLTA bekerja melalui sebuah turbin yang digerakkan oleh tenaga air. Untuk PLTA dengan skala besar, dapat memanfaatkan air terjun atau sungai-sungai besar dan waduk besar kemudian membendungnya tersebut agar aliran air dapat terkonsentrasi dan menghasilkan debit aliran yang tinggi. Namun, untuk sungai-sungai dengan aliran rendah pembangkit listrik yang dibuat umumnya dinamakan Pembangkit Listrik Tenaga Mikro Hidro atau PLTMH.

Energi hidro merupakan sumber energi terbarukan yang sangat ekonomis dan bebas polusi. Energi ini dapat digunakan dan diubah menjadi listrik. Konversi energi ini dilakukan melalui pembangkit listrik tenaga air. Pembangkit listrik jenis ini tidak meninggalkan emisi gas rumah kaca seperti yang dihasilkan oleh pembangkit listrik yang menggunakan energi fosil. Tidak seperti sumber energi terbarukan lainnya, air akan terus menghasilkan energi tanpa henti dan ketersediaannya akan terus dihasilkan oleh siklus hidrologi. Pembangkit listrik tenaga air dihasilkan

42 Setiawan, Yudi, dkk.; Kinerja Putaran Rotor Turbin Air Screw Archimedes Dengan Variasi Kemiringan Sudut Turbin 
dari energi potensial air yang diubah menjadi energi mekanik oleh turbin. Dengan memanfaatkan ketinggian dan kecepatan air, energi tersebut kemudian diubah menjadi energi listrik dengan bantuan generator.

Turbin air tipe ulir atau dikenal juga dengan Archimedes Screws Turbine merupakan salah satu jenis turbin air yang berpotensi sebagai pembangkit listrik skala kecil [1]. Turbin air tipe ulir ini sangat ramah lingkungan, dilengkapi dengan sudu berbentuk heliks yang mengelilingi sebuah poros [2]. Selain itu turbin ini dapat beroperasi pada head yang rendah, hingga $10 \mathrm{~m}$ [3][4][5], sehingga sangat cocok diterapkan pada sungai-sungai yang ada di wilayah Indonesia. Hal ini mampu mengatasi permasalahan transmisi listrik jarak jauh yang sulit untuk dijangkau oleh Pemerintah.

Penelitian tentang turbin angin ulir Archimedes sudah banyak dilakukan, namun masih belum memiliki desain yang tetap untuk kondisi tertentu [5]. Beberapa penelitian dilakukan secara eksperimental untuk menemukan hubungan antara pengaruh beberapa variabel kinerja turbin, seperti pengaruh pitch, kemiringan turbin, dan sudut ulir untuk menentukan kecepatan putar yang dihasilkan turbin. [6]. Bentuk, jumlah, pitch dan kemiringan, serta dimensi sudu Screw Archimedes mempengaruhi daya yang dihasilkan [7][8]. Juliana dkk [9] mengatakan bahwa kinerja turbin sangat dipengaruhi oleh jatuhnya air, dalam hal ini adalah kemiringan sudut ulir. Berdasarkan hal tersebut, penelitian ini akan menguji pengaruh variasi kemiringan sudut, tujuannya adalah untuk melihat pengaruh antara debit, kemiringan sudut dan desain turbin terhadao kinerja prototipe turbin air screw archimedes.

\section{METODE PENELITIAN}

Metode penelitian yang digunakan dalam penulisan ini adalah metode eksperimental. Penelitian dilakukan pada aliran air yang berpotensi untuk menggerakkan turbin. Pengujian unjuk kerja turbin dilakukan pada aliran air di dekat pemukiman penduduk yang terletak di kelurahan Parit Lalang Kota Pangkalpinang, Provinsi Bangka Belitung. Penelitian dilakukan secara alamiah berdasarkan aliran air yang terjadi di lapangan. Pengukuran debit aliran dilakukan tiga kali agar diketahui rata-rata debit yang nominalnya digunakan sebagai justifikasi debit aliran yang terjadi.

Diagram alir penelitian dapat dilihat pada gambar 1 berikut ini:

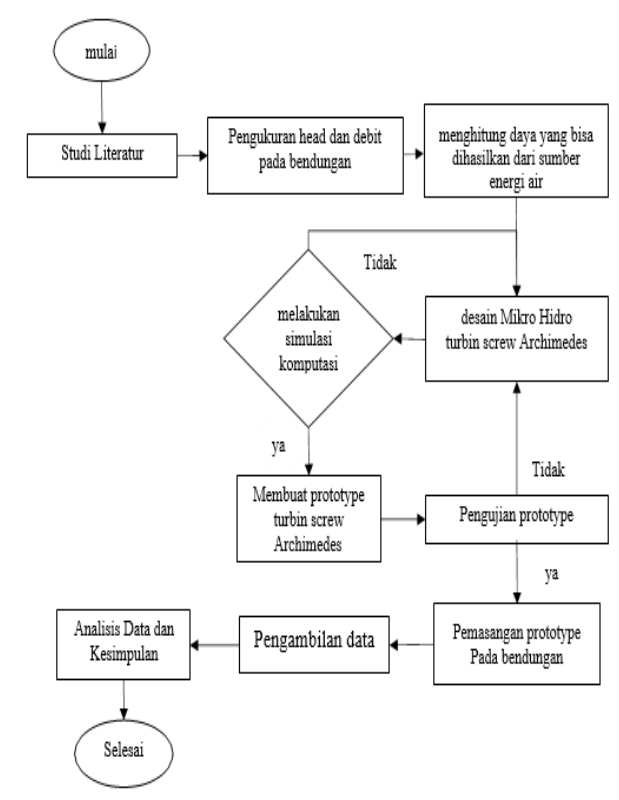

Gambar 1 Alir penelitian

Turbin didesain menggunakan software gambar dengan dengan mempertimbangkan berbagai aspek, parameter desain turbin dapat dilihat pada tabel 1 berikut ini:

Tabel 1 Parameter desain turbin

\begin{tabular}{lll}
\hline Parameter & Nilai & Satuan \\
\hline Panjang turbin (L) & 1 & meter \\
\hline Diameter luar poros & 0.3 & meter \\
\hline $\begin{array}{l}\text { Diameter dalam } \\
\text { poros }\end{array}$ & 0.254 & meter \\
\hline $\begin{array}{l}\text { Sudut kemiringan } \\
(\alpha)\end{array}$ & $30,35,40$ & Derajat \\
\hline Pitch & 0.13 & meter \\
\hline
\end{tabular}

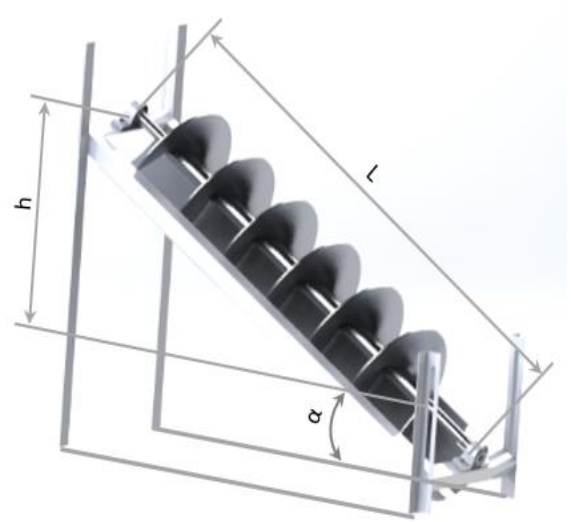

Gambar 2 Desain Instalasi turbin

43 Setiawan, Yudi, dkk.; Kinerja Putaran Rotor Turbin Air Screw Archimedes Dengan Variasi Kemiringan Sudut Turbin 
Gambar 2 menunjukkan penelitian prototipe turbin air screw archimedes. Prinsip kerja PLTMH adalah air mengalir masuk ke dalam tabung ulir. Perbedaan ketinggian yang terjadi antara upstream dan downstream akan menimbulkan gaya tekan yang mendorong dinding ulir untuk menghasilkan putaran rotor. Putaran rotor ditransmisikan menggunakan pully dan belt menuju poros generator dengan perbandingan 1:5. Putaran poros generator diukur menggunakan tachometer.

Daya teoritis turbin dihitung menggunakan rumus berikut ini:

$$
P=\rho \cdot h \cdot g \cdot Q
$$

Dimana:

$\mathrm{P}=$ Daya teoritis turbin (watt)

$\mathrm{h}=$ head $(\mathrm{m})$

$\mathrm{g}=$ gravitasi $\left(\mathrm{m} / \mathrm{dtk}^{2}\right)$

$\mathrm{Q}=$ debit aliran $\left(\mathrm{m}^{3} / \mathrm{dtk}\right)$

Untuk menghitung debit aliran digunakan formula berikut ini [9]:

$$
Q=\frac{\text { Volume wadah }}{\text { waktu untuk memenuhi wadah }}
$$

Sedangkan untuk mengukur head, menggunakan formula [10]:

$$
\sin \alpha=y_{L}
$$

Dimana:

Tan $\alpha=$ kemiringan sudut (derajat)

$\mathrm{Y}=$ jarak vertical $(\mathrm{m})$

$\mathrm{L}=$ panjang screw $(\mathrm{m})$

\section{HASIL DAN PEMBAHASAN}

Pengujian prototipe Turbin Air Screw Archimedes telah dilakukan pada aliran iar yang terletak di Kelurahan Paritlalang Pangkalpinang. Berdasarkan hasil pengukuran debit air didapat debit alir pada penelitian ini adalah sebesar 7 liter/detik atau $0,007 \mathrm{~m}^{3} /$ detik. Sedangkan head turbin dapat dilihat pada tabel 2 berikut:

\section{Tabel 2 Data hasil Eksperimen}

\begin{tabular}{lll}
\hline Type Turbin & Sudut (Derajat) & Head $(\mathrm{m})$ \\
& & \\
\hline \multirow{2}{*}{ Screw } & 30 & 0,5 \\
Archimedes & 35 & 0,57 \\
& 40 & 0,65 \\
\hline
\end{tabular}

Instalasi pengujian dapat dilihat pada gambar 3 berikut ini:

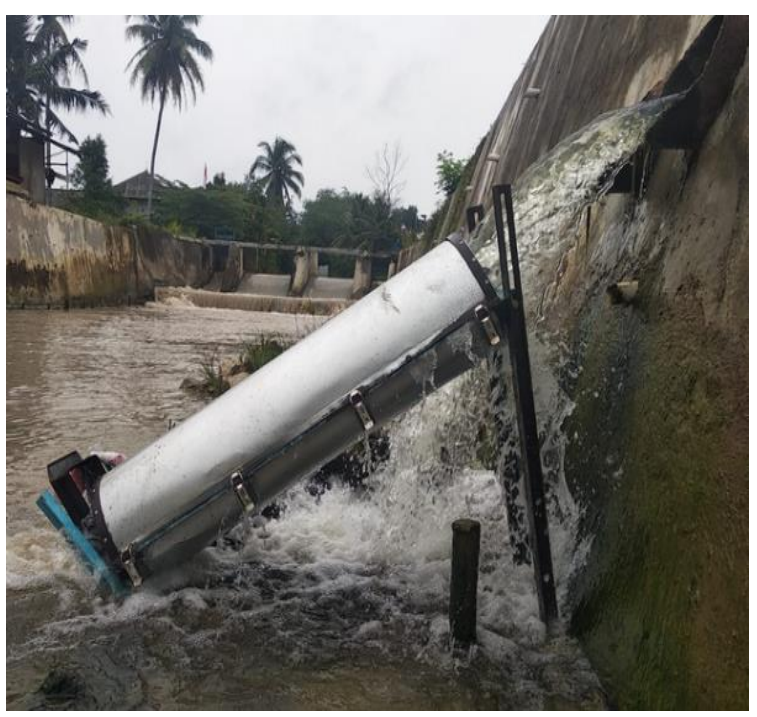

\section{Gambar 3 Pengujian turbin di lapangan}

Hasil penelitian menujukkan bahwa kemiringan sudut turbin screw Archimedes memberikan pengaruh terhadap putaran yang dihasilkan. Berikut ini data hasil penelitian:

Tabel 3 Data hasil Eksperimen

\begin{tabular}{lll}
\hline Type Turbin & $\begin{array}{l}\text { Sudut } \\
\text { (Derajat) }\end{array}$ & $\begin{array}{l}\text { Putaran } \\
\text { (rpm) }\end{array}$ \\
\hline \multirow{3}{*}{ Screw } & 30 & 794 \\
Archimedes & 35 & 885 \\
& 40 & 930 \\
\hline
\end{tabular}

Dari tabel 3 dapat dilihat bahwa kemiringan sudut yang berimbas pada jatuhnya air memberikan pengaruh signifikan. Pada sudut $30^{\circ}$ putaran rotor yang dihasilkan adalah $794 \mathrm{Rpm}$, sedangkan pada $40^{\circ}$, putaran poros yang dihasilkan adalah $885 \mathrm{rpm}$, putaran tertinggi dihasilkan oleh sudut $40^{\circ}$ yaitu sebesar $930 \mathrm{Rpm}$.

Secara signifikan didapatkan bahwa semakin besar kemiringan sudut screw turbin, maka putaran poros semakin tinggi. Hal ini memungkinkan daya yang dihasilkan juga akan naik. Besarnya debit alir juga sangat mempengaruhi putaran rotor turbin yang dihasilkan. Posisi jatuhnya air yang mengenai dinding screw untuk memberikan daya dorong juga sangat mempengaruhi putaran rotor yang dihasilkan.

Perhitungan daya teoritis dari turbin akan dihitung dengan property densitas air $1000 \mathrm{~g} / \mathrm{m}^{3}$, gravitasi $9,81 \mathrm{~m} / \mathrm{dtk}^{2}$. Dengan head yang semakin

44 Setiawan, Yudi, dkk.; Kinerja Putaran Rotor Turbin Air Screw Archimedes Dengan Variasi Kemiringan Sudut Turbin 
tinggi, maka secara teori potensi daya turbin juga akan naik. Perhitungan potensi daya turbin teoritis dapat dilihat pada gambar 4 .

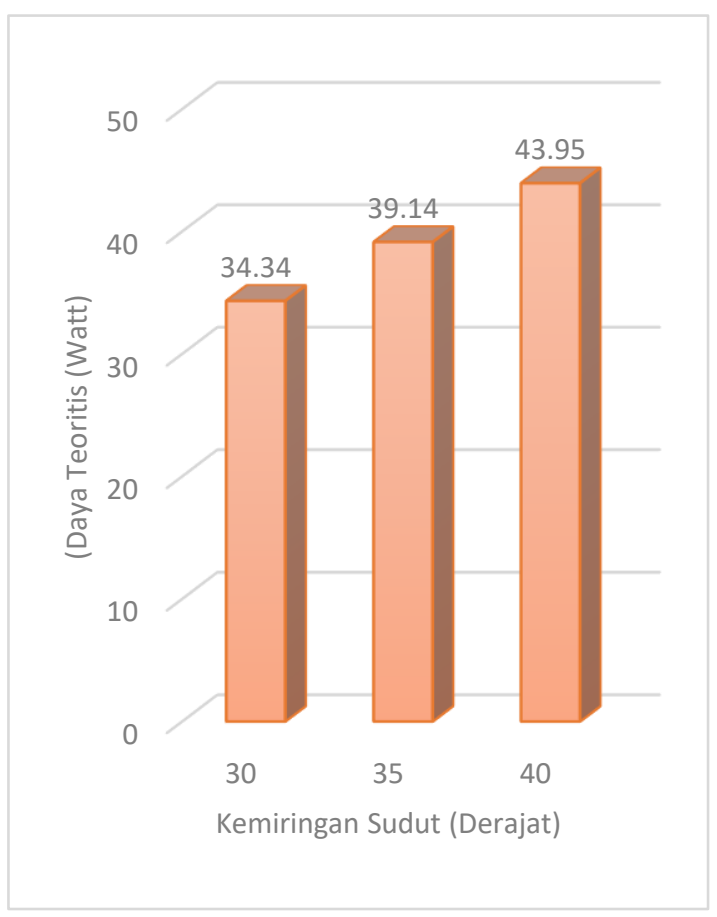

\section{Gambar 4 Grafik kemiringan sudut Vs Daya Teoritis Turbin}

Dari gambar 4 dapat dilihat bahwa turbin memiliki potensi daya yang mampu dibangkitkan hingga 43,95 watt. Potensi terbesar ini didapat pada turbin yang diletakkan dengan kemiringan 40 derajat.

\section{KESIMPULAN}

Penelitian tentang pengaruh kemiringan sudut screw turbin Archimedes terhadap kinerja turbin dapat telah dilakukan. Hasil penelitian menunjukkan bahwa kemiringan sudut turbin memberikan hasil yang bervariasi. Untuk sudut $30^{\circ}, 35^{\circ}$ dan $40^{\circ}$ menunjukkan bahwa semakin tinggi sudut kemiringan maka semakin tinggi pula putaran rotor screw. Pada debit alir 7 liter/detik, kinerja terbaik turbin didapat dari kemiringan sudut $40^{\circ}$ dengan besar putaran $930 \mathrm{Rpm}$ dengan potensi daya listrik sebesar 43,95 watt.

\section{UCAPAN TERIMA KASIH}

Penulis mengucapkan terima kasih kepada Universitas Bangka Belitung melalui
Lembaga Penelitian dan Pengabdian Kepada Masyarakat yang telah mendanai penelitian ini dengan skema Penelitian Dosen Tingkat Jurusan (PDTJ) Tahun 2021 dengan nomor kontrak PDTJ 255.F/UN50/L/PP/2021.

\section{DAFTAR PUSTAKA}

[1] Yoosef Doost A and Lubitz W D, Archimedes screw turbines: A sustainable development solution for green and renewable energy generation-a review of potential and design procedures Sustain, 2020, 12.

[2] Müller G and Senior J, 2009, Simplified theory of Archimedean screws J. Hydraul. Res. 47 666-9.

[3] Gogoi P, Handique M, Purkayastha S and Newar K, 2018, Potential of Archimedes Screw Turbine in Rural India Electrification: A Review ADBU J. Electr. Electron. Eng. 2 305.

[4] Dellinger G, Garambois P A, Dellinger N, Dufresne M, Terfous A, Vazquez $\mathrm{J}$ and Ghenaim A, 2018, Computational fluid dynamics modeling for the design of Archimedes Screw Generator Renew. Energy 118 847-57.

[5] Siswantara A I, Warjito, Budiarso, Harmadi R, Gumelar M H and Adanta D, 2019, Investigation of the $\alpha$ angle's effect on the performance of an Archimedes turbine Energy Procedia 156 458-62.

[6] Budiarso, Warjito, Dendy Adanta, M.H.G. Syafei, 2017, Development of Archimedes Turbine Research: Review Paper Proceeding Semin. Nas. Tah. Tek. Mesin XVI (SNTTM XVI) 177-81.

[7] Rorres C, The Turn of the Screw: Optimal Design of an Archimedes Screw J. Hydraul. Eng. ,2000, 126 72-80

[8] Nugroho A D, Kajian Teoritik Pengaruh Geometri Dan Sudut Kemiringan Terhadap Kinerja Turbin Archimedes Screw Conf. Senat. STT Adisutjipto Yogyakarta, 2017, 3

[9] Julianan I Putu, Weking Ibi Antonio, Jasa Lie, 2018, Pengaruh Sudut Kemiringan Head Turbin Ulir dan Daya Putar Turbin Ulir dan Daya Output Pada Pembangkit Listrik Tenaga Mikro hidro, Majalah Ilmiah Teknologi Elektro, Vol. 17, No.3 pp 393-400. 
[10] Karim M, Wildan, Hermawan, Aditya Chandra, Haryudo subuh Isnur, Kajian Kemiringan Blade dan Head Turbin
Archimedes terhadap Daya Keluaran Generator AC 1 Phase $3 \mathrm{~kW}, 2021$, Jurnal Teknik Elektro, Vol.10. No.1, pp 219-228. 